AperTO - Archivio Istituzionale Open Access dell'Università di Torino

\title{
Overlapping And Synchronization In The Song Of The Indris (Indri indri)
}

\section{This is the author's manuscript}

Original Citation:

Availability:

This version is available http://hdl.handle.net/2318/143748

since

Publisher:

World Scientific Publishing Co.

Terms of use:

Open Access

Anyone can freely access the full text of works made available as "Open Access". Works made available under a Creative Commons license can be used according to the terms and conditions of said license. Use of all other works requires consent of the right holder (author or publisher) if not exempted from copyright protection by the applicable law. 
Gamba M, Torti V, Bonadonna G, Guzzo G, Giacoma C (2014) Overlapping And Synchronization In The Song Of The Indris (Indri indri). In: EA Cartmill, S Roberts, H Lyn \& H Cornish, ed., The Evolution of Language: Proceedings of the 10th international conference (EvoLangX). pp. 90-97. 14-17th April, 2014. Vienna, Austria. Singapore: World Scientific Publishing Co. ISBN: 978-9814603-62-1.

\title{
OVERLAPPING AND SYNCHRONIZATION IN THE SONG OF THE INDRIS (Indri indri)
}

\author{
MARCO GAMBA \\ VALERIA TORTI \\ GIOVANNA BONADONNA \\ GREGORIO GUZZO \\ CRISTINA GIACOMA \\ Department of Life Sciences and Systems Biology, University of Torino, Via Accademia
} Albertina 13, Torino, 10123, Italy

\begin{abstract}
In Indri indri, males and females within a social group emit loud, long distance calls in a coordinated manner. An indri may start emitting a vocal utterance before the end of another individual's contribution, resulting in different degrees of overlap between individual songs. This study provides the first quantitative analysis of the individual overlap between indri males and females showing the adult pair members mainly overlap each other. The adult female song also has an effect on male singing in $35 \%$ of the cases, while the timing of a song unit could predict the occurrence of a unit sung by another group-member in only $10 \%$ of the other dyads (e.g. male-female or male-youngster).
\end{abstract}

\section{Introduction}

The interplay between synchronous and asynchronous displays in communicative interactions are based over sequential symmetry formations and symmetry breaks, which may involve postural, gestural, and vocal displays (Rotondo \& Boker, 2002; Adger-Antonikowski, 2008). Thus, it has been hypothesized that the spatio-temporal structure of the formation and breaking of symmetry can be diagnostic of social and cognitive aspects of human dyadic 
relationships (Boker \& Rotondo, 2002). Moreover, it has been reported that gender and dominance influence dyad interactions affecting synchrony and symmetry of the behavioral displays (Rotondo \& Boker, 2002).

Non-verbal communication in nonhuman primates may have been the substrate for the development of 'protolinguistic' forms of communication (Bickerton, 2000). Nonhuman primates long distance calls have been often seen in the frame of a larger evolutionary framework, in the perspective of human vocal and musical rhythms (Merker, 1999; 2000; Fitch, 2006; Geissmann, 2000). These series of vocal emissions have been indicated as a possible evolutionary precursor of human music (Merker, 2000; Merker \& Okanoya, 2007; Merker et al. 2009). Previous research showed that simultaneous calling patterns given by several individuals within a social group are present in various terrestrial animals including wolves (Harrington \& Asa, 2003; Mazzetti et al., 2013), coyotes (McCarley, 1975), and jackals (Jaeger et al., 1996), and in few primate species as gibbons (Geissmann, 2000; Merker, 1999) and indris (Giacoma et al., 2010; Maretti et al., 2010). According to Brown (2007), one of the features that these primate 'songs' share with music is "the matching of time".

The organization of indri is based around a socially monogamous pair where the female is dominant (Pollock, 1975). Group size usually varies between 2 and 6 animals (Torti et al., 2013). Loud singing in indris follows a sequential organization (Pollock, 1986), which shows evident species- and sex-specific features (Giacoma et al., 2010; Gamba et al., 2011) and may serve conveying different messages (Bonadonna et al., 2013; Torti et al., 2013).

We aimed to investigate whether the ability to synchronize calling during group chorusing, which may be a phylogenetic parallel to singing ability in humans, is present in Indri indri, a species who diverged from the human evolutionary path more than 65 million years ago (Steiper \& Young, 2006). Singing synchronization was expressed by measuring the percentage of overlap showed by individual singers and by evaluating whether the timing of a song unit could predict the occurrence of a unit sung by another group-member.

\section{Materials \& Methods}

\subsection{Study sites and subjects}

We observed and recorded a total of 9 groups in 3 areas of dense tropical forest in Madagascar: 3 groups in Andasibe-Mantadia National Park, Analamazaotra Reserve, 3 groups in Mitsinjo Station Forestière, and 3 groups in the Maromizaha Forest. The indris lived in socially monogamous groups composed of an adult pair and few other individuals. Very often an additional individual (often a male), whose relatedness with the adult pair is unknown, was present in the social group. We recorded 12 adult males, 12 females, and 7 youngsters. 


\subsection{Sampling and equipment}

We collected data in the field over a total of 21 months (3 months a year), between September and December from 2006 to 2012. We carried out observations of one group per day from 06:00 am to 1:00 pm. Each indri was individually recognized by natural markings. All recordings were made without the use of playback stimuli and nothing was done to modify the behavior of the indris. We have received permits for this research from "Direction des Eaux et Forêts" and "Madagascar National Parks" (formerly ANGAP). We recorded 77 songs, consisting of duets and choruses, with a maximum of six individuals singing in the same song. All utterances were recorded at a distance from 2 to 10 $\mathrm{m}$, because all the study groups were habituated. Focal animal sampling allowed the attribution of each vocalization to a signaler. Recordings were made using Sennheiser ME 66 and ME 67 and AKG CK 98 microphones, facing the focal animals (Altmann 1974) during the emission of the songs. The microphone output signal was recorded at a sampling rate of $44.1 \mathrm{kHz}$ using a solid-state digital audio recorder (Marantz PMD671, SoundDevices 702 or Olympus S100).

\subsection{Acoustic analyses}

Segments containing indri songs were edited using Praat 5.3.46 (Boersma \& Weenink 2008) and we copied each song to a single audio file (in AIFF format). We then identified each individual emission and saved this information in a Praat textgrid. Merging textgrids of different indris we estimated the overlap between individuals, which was expressed in percentage of song duration. Durations of the overlapping and non-overlapping parts of each song and timing of the centre points of each song unit were saved within Praat and exported to a Microsoft $\mathbb{C}$ Excel spreadsheet (Gamba \& Giacoma 2007; Gamba et al. 2012).

\subsection{Statistical Analyses}

Differences in the percentage of song overlap between individuals were tested using a Mann-Whitney $U$ test. The predictive power of the song unit timing in one individual over another was evaluated using the Granger Casuality test (Granger, 1969). We computed the bivariate Granger causality test in two directions for each dyad of indris singing in a chorus (Wessa, 2013) tracking whether they were males, females or youngsters. Probability values were corrected using the Sidak post-hoc method. Statistical analyses were performed using IBM SPSSStatistics 20.0 for Mac and R (Hornik, 2013). We reported means and standard deviations $( \pm \mathrm{SD})$ of the variables measured. 


\section{Results}

\subsection{Overlapping}

All of the songs we recorded showed intra-group overlapping between singers. We found that adult males and adult females had a remarkable part of their song not overlapped by others, $21 \pm 6 \%$ and $25 \pm 5 \%$ respectively. These percentages were significantly higher than those shown by youngsters of the same sex for both males $(12 \pm 7 \% ; \mathrm{N}=11, \mathrm{Z}=-2.041, \mathrm{p}=0.041)$ and females $(10+3 \% ; \mathrm{N}=$ $11, \mathrm{Z}=-2.717, \mathrm{p}=0.007)$.

Overlapping within the adult pair $\left(\mathrm{N}_{\text {pair }}=8 ; 13+5 \%\right)$ was significantly higher than the percentage of overlapping between a pair member and any other individual within social group $\left(0.004<\mathrm{p}_{\text {Sidak }}<0.013\right)$.

\subsection{Synchronization}

In indris, females' contribution to the song served as a template for males. When singing in chorus with more than one male, the female contribution covered the total duration of the song. Males, on the contrary, sang in different parts of the song, showing scarce overlapping one another.

We tested for causality between the timing of the centre-point of a unit of an emitter and the timing of the centre-point of a unit by another singer in the same chorus. We could detect an effect of youngster's singing on the pattern of adult males and females in $11 \%$ and $10 \%$ of the analyzed songs respectively. We obtained similar results $(10 \%)$ evaluating the effect of female singing on the youngsters. We found that adult male singing had an effect on the female song coordination and the youngster contribution in $33 \%$ of the samples. The highest values were found for the effect of female's song over adult males, where we found a significant result in $35 \%$ of the cases.

\section{Discussion}

Our current knowledge about primate singing is that these calls have an innate basis but they can be refined during development (Pistorio et al., 2006; Lemasson et al., 2011). Although field experience give clear indications of interindividual coordination during group chorusing, this was rarely investigated in previous primatological research.

The role of song features in the reproduction, in the intra-group and inter-group regulation in indris has been made clear by previous studies. The song units are sexually dimorphic (Giacoma et al., 2010), singing serves to maintain cohesion between group members and to regulate the spacing between neighboring 
groups (Torti et al., 2013). The song also mediates crucial aspects of indris' reproductive biology (Bonadonna et al., 2013).

Our analyses on indri showed that overlap between the male and the female of an adult pair is much more likely to occur than any other overlap between singers. This is different from previous evidence collected on singing primates where a young gibbon was often overlapping its mother (Merker \& Cox 1999) while adult sex-specific individual songs were largely separated during the song (Geissmann, 2000).

Synchronous calling bouts may provide a measure of male/female cooperation as well as vocal skill (Merker, 1999). Both these factors assure that a song is informative, signaling territorial occupation to conspecifics and introducing sexual selection pressures on the calling behavior of territorial groups. The songs may stimulate male or female migrations and the formation of new groups. In this perspective, overlapping of units emitted by the adult pair may indeed provide conspecifics at distance with a signal of their cohesion. Synchronous calling extends the reach of the signal by decibel summation and is likely to inform a greater number of conspecifics, increasing the potential mating opportunities on one hand, and acting as deterrent to potential distant intruders on the other hand. The emission of non-overlapping units may play a significant role in communicating with animals at shorter range. Indris' advertisement songs, exchanged across the territorial boundaries, may play a role in spacing neighboring groups, potentially stimulating territory intrusions, extra-pair copulations and vocal fights, or, in reverse, may deter encroachments and help conserving the existing conditions.

The evidence derived from the analysis of singing dyads units is less conclusive. The percentage of songs in which we found significance for an effect of an individual contribution on another is only $22 \%$ of the sample. The effect of female's song on the adult male's contribution appears stronger that those found in the other dyads, but still limited. Although we cannot exclude that indris have the ability to synchronize their calls during the song, the evolutionary scenario by which the human capacity to organize synchronous vocal emissions may have emerged still has to find a nonhuman parallel.

\section{Acknowledgements}

This study is part of a larger field research on Indri indri supported by the Università degli Studi di Torino and the ACP Science and Technology Programme of the ACP Group of States, with the financial assistance of the European Union, through the Projects BIRD (Biodiversity Integration and Rural Development; $N^{\circ}$ FED/2009/217077) and SCORE (Supporting Cooperation for Research and Education; Contract n. ACP RPR 118 \# 36) and by grants from the Parco Natura Viva - Centro Tutela Specie Minacciate. We are also grateful to Compagnia di San Paolo for co-financing the "Progetto 2008-10 Innovazione Laboratori didattici - Facoltà di Scienze MFN" which allowed purchasing lab 
equipment used by G.B., V.T., and G.G. during the field activities. We thank Ministère de l'Environnement et des Forêts (MEF) and Madagascar National Parks for granting the research permits. We are also grateful to GERP (Groupe d'Etudes et des Recherche sur les Primates) for allowing us to collect data in the forest under its management. We, finally, thank Rose Marie Randrianarison, Dr. Jonah Ratsimbazafy, Dr. Cesare Avesani Zaborra and Dr. Caterina Spiezio for their important role in the organization of the Maromizaha field station, all the research and international guides, Lanto and Mamatin for their help and logistic support, and Dr Olivier Friard for help with the computational analyses. The contents of this document are the sole responsibility of the authors and can under no circumstances be regarded as reflecting the position of the European Union.

\section{References}

Adger-Antonikowski, A. (2008). A Functionalist Perspective of Language Ability and Behavioral Synchrony in the Development of Emotion Regulation. Albany, USA: UMI Dissertations Publishing.

Altmann, J. (1974). Observational study of behavior: sampling methods. Behavior, 49, 227-267 [Reprinted In L.D. Houck and L.C. Drickamer (Eds.), Foundations of Animal Behavior. U Chicago Press, 1996].

Bickerton, D. (2000). How protolanguage became language. In M. StuddertKennedy, C. Knight, J.R. Hurford (Eds.), The evolutionary emergence of language: social function and the origins of linguistic form. Cambridge, UK: Cambridge University Press.

Boersma, P., Weenink, D. (2008). Praat: doing phonetics by computer (version 5.0 27). Computer program.

Boker, S. M., Rotondo, J. L. (2002). Symmetry building and symmetry breaking in synchronized movement. Advances in consciousness research, 42, 163174.

Bonadonna, G., Torti, V., Randrianarison, R.M., Martinet, N., Gamba, M. \& Giacoma, C. (2013). Behavioral correlates of extra-pair copulation in Indri indri. Primates, DOI 10.1007/s10329-013-0376-0.

Brown, S. (2007). Contagious heterophony: A new theory about the origins of music. Musicae Scientiae, 1, 3-26.

Fitch, W.T. (2006). The biology and evolution of music: a comparative perspective. Cognition, 100, 173-215.

Gamba, M., Giacoma, C. (2007). Quantitative acoustic analysis of the vocal repertoire of the crowned lemur. Ethology Ecology And Evolution, 19, 323343.

Gamba, M., Favaro, L., Torti, V., Sorrentino, V., Giacoma, C. (2011). Vocal tract flexibility and variation in the vocal output in wild indris. Bioacoustics, 20, 251-266. 
Gamba, M., Friard, O., \& Giacoma, C. (2012). Vocal tract morphology determines species-specific features in vocal signals of lemurs (Eulemur). International Journal of Primatology, 33, 1453-1466.

Geissmann, T. (2000). Gibbon song and human music from an evolutionary perspective. In N.L. Wallin, B. Merker and S. Brown (Eds.), The Origins of Music (pp. 103-123). Cambridge, MA: The MIT Press.

Giacoma, C., Sorrentino, V., Rabarivola, C., \& Gamba, M. (2010). Sex differences in the song of Indri indri. International Journal of Primatology, 31, 539-551.

Granger, C.W.J. (1969). Investigating Causal Relations by Econometric Models and Cross-Spectral Methods. Econometrica, 37, 424-438.

Harrington, F.H., \& Asa, C.S. (2003). Wolf communication: behavior, ecology, and conservation. In L.D. Mech and L. Boitani (Eds.), Wolves: Behavior, Ecology and Conservation (pp. 96-99). Chicago: University of Chicago Press.

Jaeger, M.M., Pandit, R.K., \& Haque, E. (1996). Seasonal Differences in Territorial Behavior by Golden Jackals in Bangladesh: Howling versus Confrontation. Journal of Mammalogy, 77, 768-775.

Lemasson, A., Ouattara, K., Petit, E.J., \& Zuberbuhler, K. (2011). Social learning of vocal structure in anon-human primate. BMC Evolutionary Biology, 11, 362.

Maretti, G., Sorrentino, V., Finomana, A., Gamba, M., \& Giacoma, C. (2010). Not just a pretty song: an overview of the vocal repertoire of Indri indri. Journal of anthropological sciences, 88, 151-165.

Mazzini, F., Townsend, S.W., Viranyi, Z., \& Range, F. (2013). Wolf howling is mediated by relationship quality rather than underlying emotional stress. Current Biology, 23, 1677-1680.

McCarley, H. (1975). Long-distance vocalizations of coyotes (Canis latrans). Journal of Mammalogy, 56, 847-856.

Merker, B. (1999). Synchronous chorusing and the origins of music. Musicae Scientiae, Special issue 1999-2000, 59-73.

Merker, B. (2000). Synchronous chorusing and human origins. In N.L. Wallin, B. Merker and S. Brown (Eds.), The Origins of Music (pp. 315-327). Cambridge, MA: The MIT Press.

Merker, B., \& Cox, C. (1999). Development of the female great call in Hylobates gabriellae: A case study. Folia Primatologica, 70, 96-106.

Merker, B., \& Okanoya, K. (2007). The natural history of human language: Bridging the gaps without magic. In C. Lyon, L. Nehaniv and A. Cangelosi (Eds.), Emergence of communication and language (pp. 403-420). London: Spring-Verlag.

Merker, B., Eckerdal, M., \& Eckerdal, P. (2009). On the role and origin of isochrony in human rhythmic entrainment. Cortex, 45, 4-17.

Pistorio, A., Vintch, B., \& Wang X. (2006). Acoustic analyses of vocal development in a New World primate, the common marmoset (Callithrix 
jacchus). Journal of the Acoustical Society of America, 2006; 120, 16551670.

Pollock, J.I. (1975). The social behavior and ecology of Indri indri. PhD thesis, University College London.

Rotondo, J. L., Boker, S. M. (2002). Behavioral synchronization in human conversational interaction. Advances in consciousness research, 42, 151-162.

Torti, V., Gamba, M., Rabemananjara, Z.H., \& Giacoma, C. (2013). The songs of the indris: contextual variation in the long distance calls of a lemur. Italian Journal of Zoology, DOI: 10.1080/11250003.2013.845261.

Steiper, M.E., \& Young, N.M. (2006). Primate molecular divergence dates. Molecular Phylogenetics and Evolution, 41, 384-394.

Wessa, P. (2013). Free Statistics Software, Office for Research Development and Education, version 1.1.23-r7, URL http://www.wessa.net/ 